\title{
Dispersive Surface Energy and Acid-Base Parameters of Tosylate Functionalized Poly(ethylene glycol) via Inverse Gas Chromatography
}

\author{
Feyza Sesigur, Dolunay Sakar, Ozlem Yazici, Fatih Cakar, \\ Ozlem Cankurtaran, and Ferdane Karaman \\ Department of Chemistry, Yildiz Technical University, Esenler, 34220 Istanbul, Turkey \\ Correspondence should be addressed to Dolunay Sakar; dolunaykar@yahoo.com
}

Received 8 May 2014; Revised 27 October 2014; Accepted 14 November 2014; Published 25 December 2014

Academic Editor: Carlos Guerrero-Sanchez

Copyright (c) 2014 Feyza Sesigur et al. This is an open access article distributed under the Creative Commons Attribution License, which permits unrestricted use, distribution, and reproduction in any medium, provided the original work is properly cited.

\begin{abstract}
An inverse gas chromatographic (IGC) study of the sorption properties of poly(ethylene glycol) modified with tosylate (PEGTOS) was presented. PEG-TOS was synthesized via the tosylation of the corresponding poly(ethylene glycol) (PEG) with p-toluenesulfonyl chloride in the basic medium. The synthesized PEG-Tos was characterized by FTIR-ATR and ${ }^{1}$ HNMR techniques. The retention diagrams of $\mathrm{n}$-hexane, $\mathrm{n}$-heptane, n-octane, $\mathrm{n}$-nonane, $\mathrm{n}$-decane, dichloromethane, chloroform, acetone, tetrahydrofuran, ethyl acetate, and ethanol on the PEG and PEG-Tos were plotted at temperatures in K between 303 and 373 by inverse gas chromatography technique. The dispersive component of the surface-free energy, $\gamma_{S}^{D}$, of studied adsorbent surface was estimated using retention times of different nonpolar organics in the infinite dilution region. Thermodynamic parameters of adsorption (free energy, $\Delta G_{A}^{S}$, enthalpy, $\Delta H_{A}^{S}$, and entropy, $\Delta S_{A}^{S}$ ), dispersive components of the surface energies, $\gamma_{S}^{D}$, and the acid, $K_{A}$, and base, $K_{D}$, constants for the PEG and PEG-Tos were calculated and the results were discussed.
\end{abstract}

\section{Introduction}

PEG is widely used in the pharmaceutical and biomedical fields. It is a nonionic polymer, soluble in water, and most common organic solvents. The incorporation of a PEG segment in a macromolecule modulates its solution properties [1]. Functionalized PEG gives opportunity to synthesize water soluble block copolymers. Tosylates are good substrates for substitution reactions. When PEG is functionalized with tosylate, it can be useful to synthesize block copolymers such as water-soluble diblock copolymer of polysulfonic diphenyl aniline and poly(ethylene glycol) [2].

Inverse gas chromatography (IGC) has been used for investigation of the interactions of polymers with various liquids [3, 4], hyperbranched aliphatic polyesters [5], block copolymers [6], polymer blends [7], nanocomposites [8], cement pastes [9], crude oils [10], surface properties of Schiff base [11], and liquid crystals [12, 13]. The method being simple, relatively rapid, with good accuracy, and of low cost and available equipment provide valuable thermodynamic information for physicochemical characterization of materials [14]. From the IGC measurements, the physicochemical properties can be obtained for polymeric systems including the weight fraction activity coefficients of solvents at infinite dilution, interaction parameters of polymers with solvents and polymers, surface, molar heat and free energies of mixing and sorption, solubility parameter, glass transition, melting points, and degree of crystallinity of polymers [15]. Using these parameters and appropriate models allow understanding of the intermolecular interaction responsible for solvation in the stationary phase.

In this study, we aimed to understand the effect of tosylate on some thermodynamic parameters and surface properties of PEG. The retention diagrams of some solvents on the PEG and PEG-Tos were obtained by IGC, and surface parameters with the studied solvents were determined. These surface properties were the dispersive component of the surface energy, basic thermodynamic parameters of adsorption, and the degree of acidity-basicity of the surface of the PEG and PEG-Tos. 


\section{Inverse Gas Chromatography Measurements under Infinite Dilution}

IGC is an adaptation of conventional gas chromatography that is used in the characterization of material surfaces. The adsorbate net retention volumes, $V_{N}$, are calculated from the expression

$$
V_{N}=Q J\left(t_{R}-t_{A}\right)\left(\frac{T}{T_{f}}\right),
$$

where $t_{R}$ is the retention time of the probe, $t_{A}$ is the retention time of air, $Q$ is volumetric flow rate measured at column outlet and at ambient temperature, $T_{f}(\mathrm{~K}), T(\mathrm{~K})$ is the column temperature, and $J$ is the James-Martin gas compressibility correction factor $[16,17]$. The interactions experienced between an adsorbate and an adsorbent can consist of two components-specific and dispersion forces. Dispersion forces, also known as London forces, are present between all molecules, regardless of their identity. Specific forces generally rely on some compatibility between the structures of the interacting molecules, either physically or electronically [18].

In the analysis of the dispersive component of the surface-free energy of solid surfaces by IGC, are used three approaches which are Riddle Jr. and Fowkes [19] (referred to as Schultz and Lavielle approach by some authors; all references are given in [19]), Dorris and Gray [20], and Flour and Papirer [21].

According to Fowkes approach, the dispersive component of the surface energy, $\gamma_{S}\left(\mathrm{Jm}^{-2}\right)$, is determined using [19]

$$
-\Delta G_{A}=R T \ln \left(V_{N}\right)=2 N a\left(\gamma_{S}^{D}\right)^{0.5}\left(\gamma_{L}^{D}\right)^{0.5}+C .
$$

Thus for a series of nonpolar probes, a plot of $R T \ln V_{N}$ against $a\left(\gamma_{L}^{D}\right)^{0.5}$ will give a slope of $2 N\left(\gamma_{S}^{D}\right)^{0.5}$. Values of $a\left(\gamma_{L}^{D}\right)^{0.5}$ of nonpolar solvents are found in the literature [19]. The specific component of the free energy is determined from the n-alkane plot of $R T \ln V_{N}$ against $a\left(\gamma_{L}^{D}\right)^{0.5}$. The distance between the ordinate values of the polar probe datum point and the $\mathrm{n}$-alkane reference line gives the specific component of the surface-free energy, $-\Delta G_{A}^{S}$.

An equation may be written for this procedure,

$$
-\Delta G_{A}^{S}=R T \ln \left(\frac{V_{N, n}}{V_{N, \text { ref }}}\right),
$$

where $V_{N, n}$ and $V_{N, \text { ref }}$ are the retention volume for the polar probe and the retention volume for the nonpolar reference line, respectively.

The adsorption of a polar probe onto the adsorbent surface leads to a change in the enthalpy of the system and the entropy of the system. These factors are related to the energy of adsorption by the equation

$$
\Delta G_{A}^{S}=\Delta H_{A}^{S}-T \Delta S_{A}^{S} .
$$

Here, $\Delta H_{A}^{S}$ is the adsorption enthalpy by Lewis acid-base interactions, $\Delta S_{A}^{S}$ is the adsorption entropy Lewis acid-base interactions, and $T$ is the column temperature. For each polar probe, $\Delta H_{A}^{S}$ and $\Delta S_{A}^{S}$ can be determined from a plot of $-\Delta G_{A}^{S} / T$ against $1 / T$.

The surface Lewis acidity and basicity constants, $K_{A}$ and $K_{D}$, may be calculated from the following equation

$$
-\Delta H_{A}^{S}=K_{A} \mathrm{DN}+K_{D} \mathrm{AN}^{*} .
$$

Here, $\mathrm{DN}$ and $\mathrm{AN}^{*}$ are Gutmann's donor and modified acceptor numbers, respectively. The $\mathrm{AN}^{*}, \mathrm{DN}$, and $a\left(\gamma_{L}^{D}\right)^{0.5}$ values of the polar probes are taken from [19].

$K_{A}$ and $K_{B}$ are obtained from a plot of $-\Delta H_{A}^{S} / \mathrm{AN}^{*}$ versus DN/AN* with $K_{A}$ as the slope and $K_{D}$ as the intercept. Parameters $K_{A}$ and $K_{D}$ reflect the ability of the examined surface to act as an electron acceptor and electron donor, respectively [19].

\section{Experimental Part}

3.1. Synthesis of Tosylated Poly(ethylene glycol). Polyethylene glycol 400 for synthesis $\left(\mathrm{HO}\left(\mathrm{CH}_{2} \mathrm{CH}_{2} \mathrm{O}\right)_{n} \mathrm{H}\right)$ (average molecular mass $380-420 \mathrm{~g} / \mathrm{mol}, T_{g}=-5^{\circ} \mathrm{C}$ ) and $p$-toluenesulfonyl chloride (99wt\%) were purchased from Merck. PEG-Tos was synthesized via the tosylation of the corresponding PEG with $p$-toluenesulfonyl chloride in a twophase system containing THF/water: $8 / 3 \mathrm{v} / \mathrm{v}$ in the presence of $\mathrm{NaOH}$ (in Scheme 1). The detailed procedure can be described as follows. An amount of 0.0936 mol of PEG-400 and an amount of $25 \mathrm{~mL}$ of THF were introduced in a $250 \mathrm{~mL}$, round-bottom flask possessing a magnetic stirrer. $\mathrm{NaOH}$, $0.1398 \mathrm{~mol}$, dissolved in $30 \mathrm{~mL}$ of water was introduced into the flask, and the system was mixed for a few minutes in a salt-ice bath around $-5^{\circ} \mathrm{C}$ until a white emulsion was formed. Tosyl chloride ( $\mathrm{Tos} \mathrm{Cl}$ ) was divided into two parts, and the first $0.02885 \mathrm{~mol}$ of $\mathrm{TosCl}$ dissolved in $30 \mathrm{~mL}$ of THF was added dropwise within $1 \mathrm{~h}$, and another $0.06688 \mathrm{~mol}$ of Tos Cl (total $0.09573 \mathrm{~mol}$ ) dissolved in $25 \mathrm{~mL}$ of THF was added within another $1 \mathrm{~h}$ also dropwise with intensive stirring. The reaction was continued for $4 \mathrm{~h}$ at $-5^{\circ} \mathrm{C}$, after which the reaction temperature was raised up to room temperature and kept at that temperature for $18 \mathrm{~h}$. After reaction, $100 \mathrm{~mL}$ of diethyl ether was added, and then two layers were formed. The water layer was extracted three times with diethyl ether (30 $\mathrm{mL}$ each time), and the entire diethyl ether phase was washed with water a few times until being neutral $(\mathrm{pH}=$ 7). The diethyl ether solution was dried by passing through an anhydrous $\mathrm{Na}_{2} \mathrm{SO}_{4}(30 \mathrm{~g})$ column until a clear diethyl ether solution was obtained. The diethyl ether was removed with a rotary evaporator. The synthesized PEG-Tos was a transparent liquid. The yield was about $80 \mathrm{wt} \% .{ }^{1} \mathrm{HNMR}$ and Fourier transform infrared (FTIR) measurements on an attenuated total reflection accessory (ATR) were carried out on a $500 \mathrm{MHz}$ INOVA-500 and a Perkin Elmer FTIR-ATR, respectively.

3.2. Inverse Gas Chromatography Measurements. Studied solvents such as n-hexane (Hx), n-heptane (Hp), n-octane $(\mathrm{O})$, n-nonane $(\mathrm{N}), \mathrm{n}$-decane $(\mathrm{D})$, dichloromethane (DCM), 


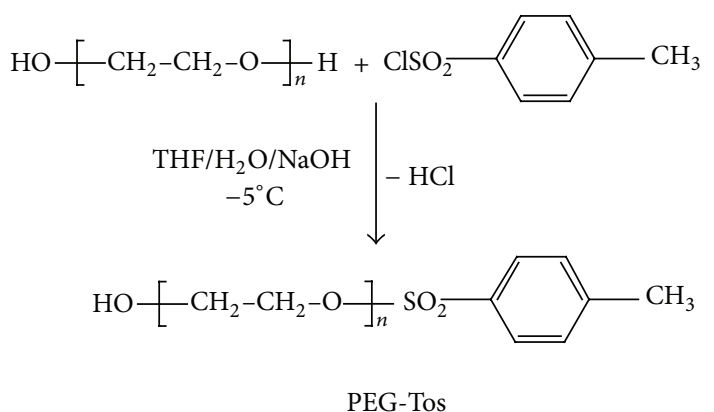

Scheme 1: Synthesis of PEG-Tos.

chloroform (Ch), acetone (Ac), tetrahydrofuran (THF), and ethyl acetate (EA) were also taken from Merck. They were HPLC grade at $99 \%$ purity in molecular sieve and used without further purification. The support materials being Chromosorb W (AW-DMCS-treated, 80/100 mesh) were supplied from Merck. Silane treated glass wool used to plug the ends of the column was obtained from Alltech Associates, Inc.

A Hewlett-Packard 6890 Model gas chromatograph with a thermal conductivity detector was used to measure the retention time of the solvents in this study. The column was stainless steel tubing with $3.2 \mathrm{~mm}$ o.d. and $0.5 \mathrm{~m}$ in length. The PEG and PEG-Tos polymers were coated on the support by slowly evaporation of chloroform as stirring the Chromosorb $\mathrm{W}$ in the polymer solution. The amount of coated polymer on the support was determined as $10 \%$ by calcination. Trace amount of solvent was injected into the chromatograph. Small volumes of vapor probes were injected manually to achieve the infinite dilution conditions. The column was conditioned at $393 \mathrm{~K}$ for $24 \mathrm{~h}$ under helium atmosphere at flow rate $30 \mathrm{~cm}^{3} / \mathrm{min}$. Zero coverage conditions were reached by injecting $5 \mu \mathrm{L}$ of vapors of the different probes. In these conditions the interactions between adsorbate molecules themselves are negligible and the thermodynamic parameters, calculated using the retention time of each probe, depend only on the adsorbate/adsorbent interactions. In the case of IGC measurement at infinite dilution, minor amounts of vapors of the test solutes are injected into the column filled with polymer, permitting the lateral interactions between the adsorbed molecules to be neglected and the retention volumes are independent of the injection sample size.

Experiments were carried out repeatedly (and reproducibly) at different temperatures. Retention data of the test solutes were collected between 303 and $373 \mathrm{~K}$.

\section{Results and Discussion}

4.1. Characterization of PEG-Tos. The aim of tosylation of PEG was to obtain PEG with active end group to synthesize water soluble block copolymer. For this purpose, tosylated PEG was synthesized (Scheme 1) and examined by FTIR-ATR (Figure 1) and ${ }^{1}$ HNMR (Figure 2).

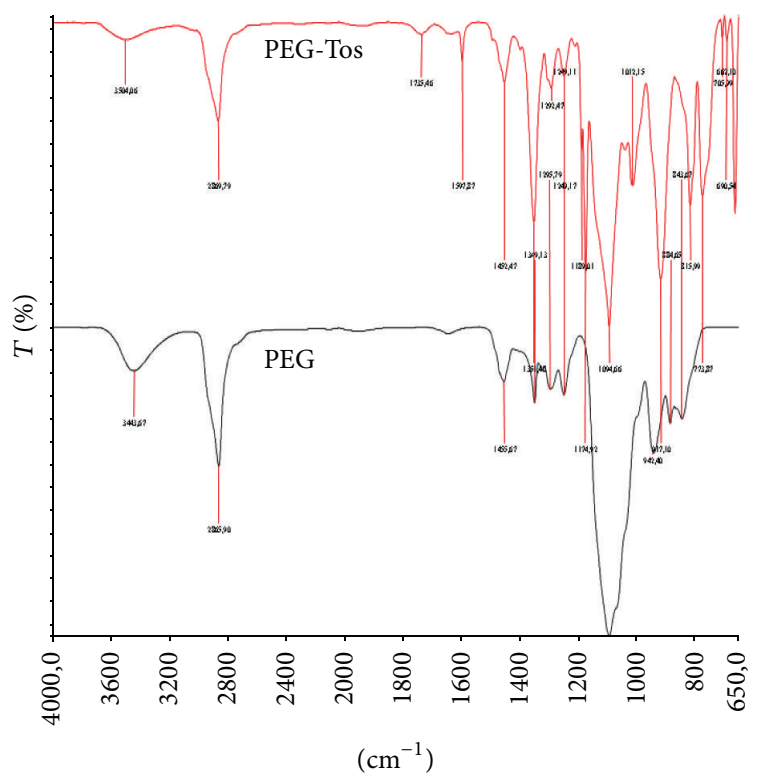

Figure 1: FTIR-ATR spectrum of PEG-Tos and PEG.

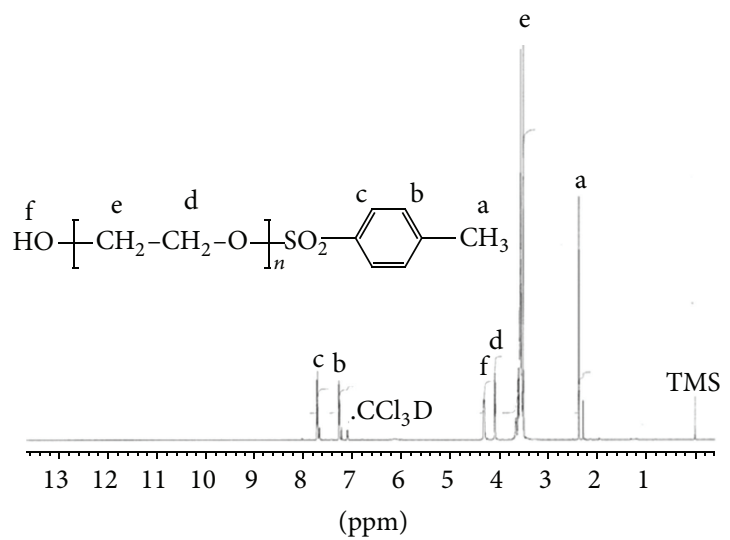

FIGURE 2: ${ }^{1}$ HNMR spectrum of PEG-Tos in deuterated chloroform.

In the FTIR-ATR spectra of PEG and PEG-Tos presented in Figure 1, the characteristic absorption peak at about $3500 \mathrm{~cm}^{-1}$, due to the hydroxide end group of PEG, did not disappear in the spectrum of PEG-Tos and new peaks at 1735 , 1597,1189 , and $773 \mathrm{~cm}^{-1}$ emerged after tosylation, which could be assigned to the stretching vibrations of the substituting phenyl hydrogen, of -COO in -SOOOC and of -SOOO in PEG-Tos, respectively. This indicates that the tosyl was connected to the PEG end generating the PEG tosylate.

Furthermore, the ${ }^{1}$ HNMR spectra of PEG-Tos revealed a hydroxide group capped with tosylate (see Figure 2). The signal due to the oxymethylene connected with tosylate was shifted to $4.05 \mathrm{ppm}(2 \mathrm{H}$, peak $\mathrm{d})$, whereas the signal due to the oxymethylene, which was connected to the hydroxide end group of PEG before substitution, was located at $3.80 \mathrm{ppm}$. The other signals that appeared at 7.70, $7.22 \mathrm{ppm}$, and $2.4 \mathrm{ppm}$ could be assigned to the phenyl hydrogen $(4 \mathrm{H}$, peaks $\mathrm{b}$ and c) and methyl hydrogen $(3 \mathrm{H}$, peak a) of the tosylate moiety. 


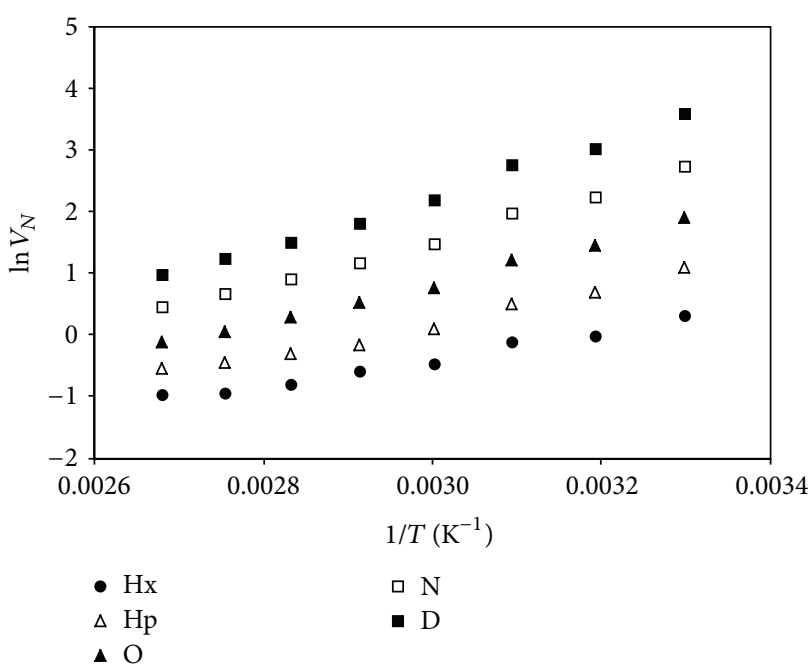

(a) Nonpolar solvents

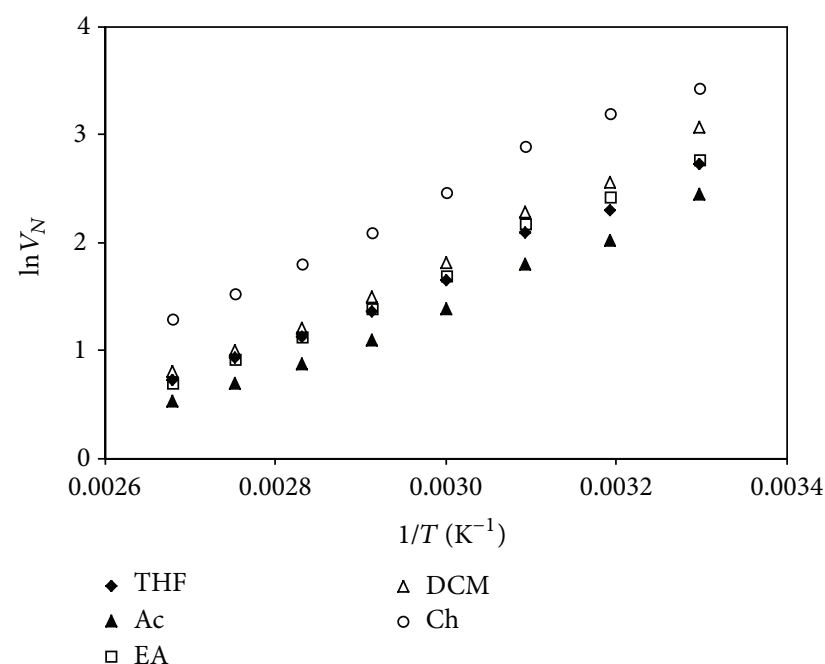

(b) Polar solvents

FIgURE 3: The retention diagrams, $V_{N}$, of (a) nonpolar solvents and (b) polar solvents adsorbed onto PEG.

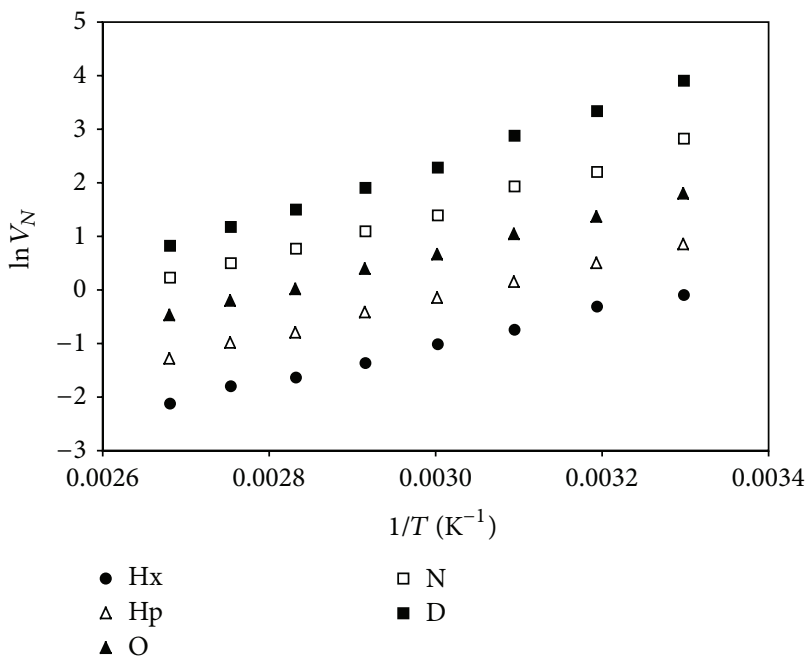

(a) Nonpolar solvents

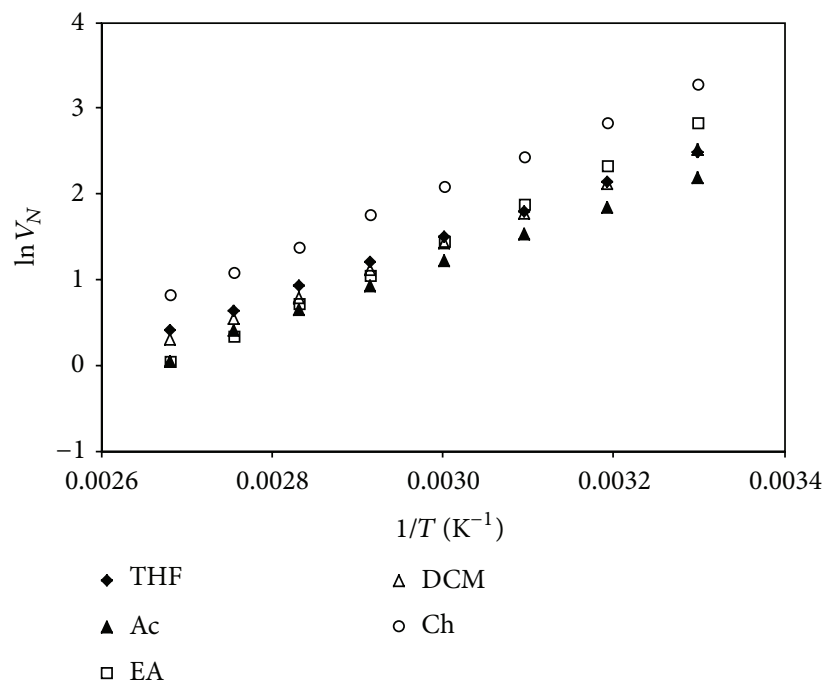

(b) Polar solvents

FIGURE 4: The retention diagrams, $V_{N}$, of (a) nonpolar solvents and (b) polar solvents adsorbed onto PEG-Tos.

4.2. Surface Characterization of PEG and PEG-Tos via IGC. The net retention volumes, $V_{N}$, of the nonpolar and polar solvents on the PEG and PEG-Tos were obtained from IGC measurements between 303 and $373 \mathrm{~K}$ using (1). The retention diagrams of nonpolar and polar solvents on PEG and PEG-Tos were given in Figures 3(a), 3(b), 4(a), and 4(b), respectively.

The diagrams drawn for PEG and PEG-Tos showed the same trends with increasing temperature.

The Fowkes equation (2) [19] was used to determine the dispersive component of the surface-free energy, $\gamma_{S}^{D}$, over a range of studied temperatures and calculated values of $R T \ln V_{N}$ were plotted against $a\left(\gamma_{L}^{D}\right)^{0.5}$. An example of the pattern of results obtained was given in Figure 5 for PEG and Figure 6 for PEG-Tos at $303 \mathrm{~K}$.

The linearity was obtained by the nonpolar solvents at the studied temperature ranges. The slope $\left(2 N \sqrt{\gamma_{S}^{D}}\right)$ of the linear fit, obtained for each nonpolar solvent plot, gives the dispersive component of the surface-free energy, $\gamma_{S}^{D}$, at that temperature. The values of $\gamma_{S}^{D}$ at studied temperature ranges belonging to PEG and PEG-Tos were given in Table 1.

The $\gamma_{S}^{D}$ values of PEG and PEG-Tos at studied temperatures calculated by Fowkes method were decreasing with increasing temperature. Comparison of the data presented in Table 1 showed that $\gamma_{S}^{D}$ is higher for PEG-Tos than PEG. 


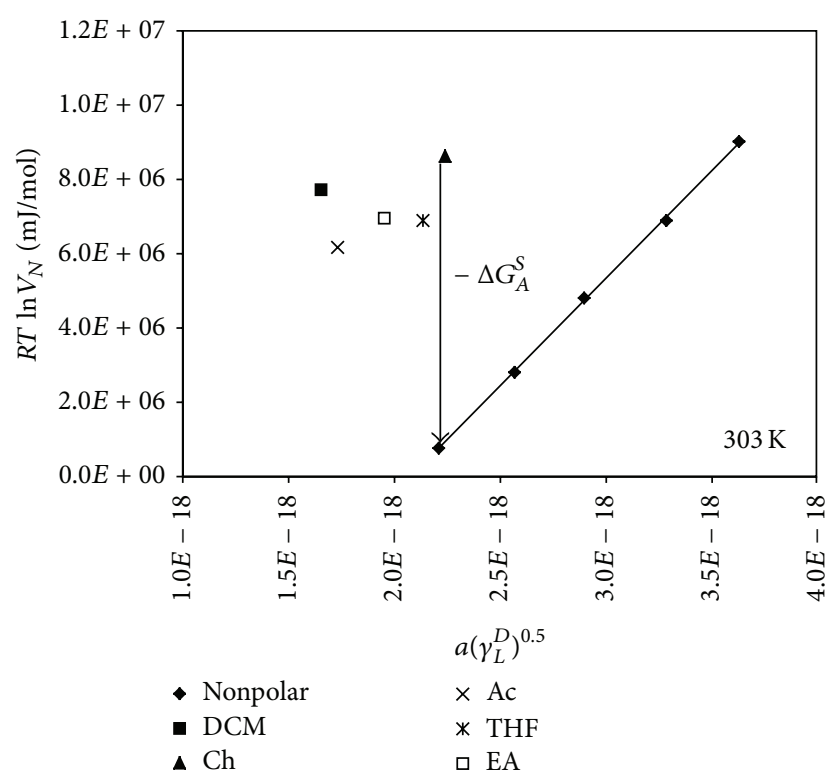

FIgURE 5: A plot of $R T \ln V_{N}$ versus $a\left(\gamma_{L}^{D}\right)^{0.5}$ for nonpolar and polar probes on PEG at $303 \mathrm{~K}$.

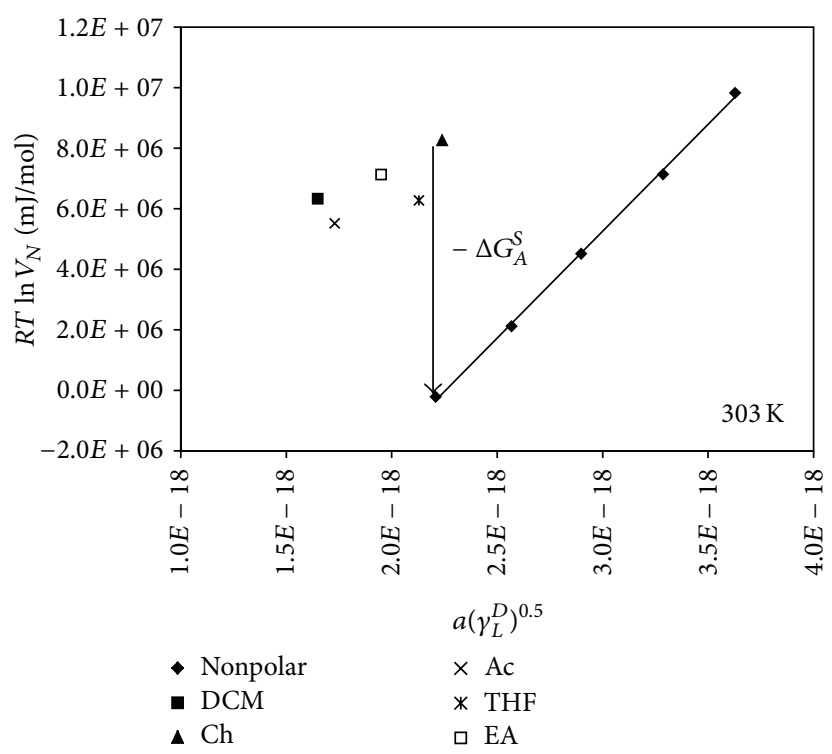

Figure 6: A plot of $R T \ln V_{N}$ versus $a\left(\gamma_{L}^{D}\right)^{0.5}$ for nonpolar and polar probes on PEG-Tos at $303 \mathrm{~K}$.

In the literature, the $\gamma_{S}^{D}$ values of PEG $\left(M_{W}=1100000, T_{m}=\right.$ $73^{\circ} \mathrm{C}$ ) were ranged from 8.57 to $13.70 \mathrm{~mJ} / \mathrm{m}^{2}$ between 340 and $400 \mathrm{~K}$ in agreement with this study. The $\gamma_{S}^{D}$ values of PEG and PEG-Tos were not so high as PVC 41.50, polypyrroles 106, and PMMA $40 \mathrm{~mJ} / \mathrm{m}^{2}$ polymers [22]. This agreement revealed that dispersive surface energy of the PEG did not change with molar mass of PEG due to the fact that PEG was used as surface energy reducing agent in silica and iron oxide surfaces [23] and PEG-Tos can be used in those surfaces instead of PEG.
TABLE 1: $\gamma_{S}^{D}$ values of PEG and PEG-Tos at studied temperatures calculated by Fowkes method.

\begin{tabular}{lcc}
\hline$T(\mathrm{~K})$ & $\gamma_{S}^{D}(\mathrm{PEG})\left({\left.\mathrm{m} J \mathrm{~m}^{-2}\right)}^{\mathrm{D}}\right.$ & $\gamma_{S}^{D}(\mathrm{PEG}-\mathrm{Tos})\left(\mathrm{mJm}^{-2}\right)$ \\
\hline 303 & 23.11 & 34.35 \\
313 & 21.23 & 29.95 \\
323 & 20.31 & 32.01 \\
333 & 18.56 & 27.85 \\
343 & 16.62 & 28.85 \\
353 & 15.87 & 28.80 \\
363 & 14.67 & 27.75 \\
373 & 12.60 & 28.90 \\
\hline
\end{tabular}

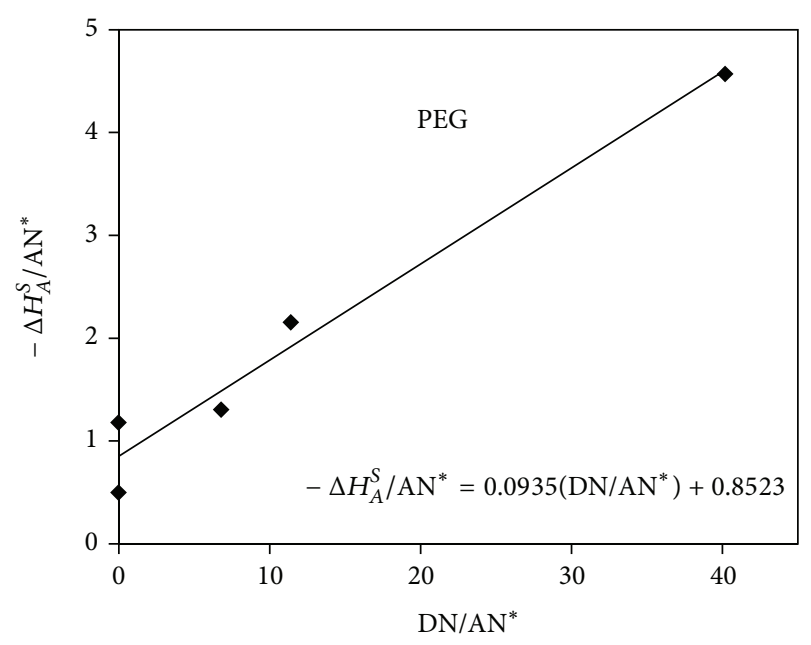

Figure 7: The plot of $-\Delta H_{A}^{S} / \mathrm{AN}^{*}$ versus DN/AN* for PEG.

$-\Delta G_{A}^{S}$ of PEG and PEG-Tos were calculated using the difference between the calculated value of $R T \ln V_{N}$ and that which was derived using (3) of the linear fit of the nonpolar reference line. The straight reference line defined the London dispersive interactions, while the polar probes lied above this line, indicating that acid-base interactions were present.

The variation of free energy of specific interactions, $-\triangle G_{A}^{S}$, between PEG and PEG-Tos and polar probes for studied temperatures was given in Table 2 .

By plotting the values of $-\Delta G_{A}^{S} / T$ against $1 / T$, the adsorption enthalpy, $\Delta H_{A}^{S}$, and the adsorption entropy, $\Delta S_{A}^{S}$, of PEG and PEG-Tos were determined for each studied polar probe and the results belonging to PEG and PEG-Tos were given in Table 3.

The $\Delta G_{A}^{S}$ values of polar solvents on PEG and PEG-Tos were affected as decreasing with increasing temperature. The studied polar solvents showed exothermic heat (Table 3 ) and positive entropy (Table 3) of sorption which was responsible for their exothermic-free energy of sorption (Table 2). The strength of the interaction between solvents and polymer was proved via the values of $\Delta H_{A}^{S}$.

The values of $K_{A}$ and $K_{D}$ were calculated using (4). The plot of $-\Delta H_{A}^{S} / \mathrm{AN}^{*}$ versus $\mathrm{DN} / \mathrm{AN}^{*}$ was given $K_{A}$ as 
TABLE 2: The variation of free energy of specific interactions, $-\Delta G_{A}^{S}\left(\mathrm{kJmol}^{-1}\right)$, between PEG and PEG-Tos and polar probes for studied temperatures.

\begin{tabular}{lcccccccccc}
\hline \multirow{2}{*}{$T(\mathrm{~K})$} & \multicolumn{2}{c}{ DCM } & \multicolumn{2}{c}{ Ch } & \multicolumn{3}{c}{ Ac } & \multicolumn{2}{c}{ THF } & \multicolumn{2}{c}{ EA } \\
& PEG & PEG-Tos & PEG & PEG-Tos & PEG & PEG-Tos & PEG & PEG-Tos & PEG & PEG-Tos \\
\hline 303 & 7.8 & 14.8 & 5.2 & 13.0 & 5.8 & 13.4 & 4.1 & 11.47 & 5.3 & 13.5 \\
313 & 6.7 & 14.0 & 4.9 & 11.7 & 4.9 & 12.7 & 3.2 & 10.7 & 4.6 & 12.4 \\
323 & 7.9 & 13.2 & 6.5 & 10.8 & 6.2 & 12.0 & 4.9 & 9.9 & 6.1 & 11.4 \\
333 & 6.8 & 14.1 & 5.6 & 12.3 & 5.2 & 13.0 & 3.9 & 11.4 & 4.9 & 12.3 \\
343 & 6.0 & 13.3 & 4.8 & 11.6 & 4.5 & 12.3 & 3.2 & 10.7 & 4.2 & 11.4 \\
353 & 5.3 & 12.4 & 4.1 & 10.6 & 3.9 & 11.5 & 2.7 & 9.9 & 3.5 & 10.4 \\
363 & 4.8 & 11.7 & 3.4 & 9.8 & 3.5 & 10.8 & 2.2 & 9.2 & 3.0 & 9.3 \\
373 & 5.9 & 11.1 & 5.0 & 9.1 & 4.7 & 9.8 & 3.7 & 8.5 & 4.4 & 8.4 \\
\hline
\end{tabular}

TABLE 3: Values of the enthalpy, $\Delta H_{A}^{S}$, and entropy, $\Delta S_{A}^{S}$, of adsorption on PEG and PEG-Tos for the polar probes.

\begin{tabular}{lcccc}
\hline Probes & \multicolumn{2}{c}{$-\Delta H_{A}^{S}\left(\mathrm{kJmol}^{-1}\right)$} & \multicolumn{2}{c}{$\Delta S_{A}^{S} \cdot 10^{3}\left(\mathrm{kJmol}^{-1} \mathrm{~K}^{-1}\right)$} \\
& PEG & PEG-Tos & PEG & PEG-Tos \\
\hline DCM & 19.4 & 29.4 & 38.4 & 47.2 \\
Ch & 11.4 & 24.8 & 19.0 & 40.5 \\
Ac & 13.7 & 26.3 & 26.3 & 42.5 \\
THF & 9.6 & 21.1 & 18.1 & 32.2 \\
EA & 13.6 & 32.8 & 26.9 & 40.5 \\
\hline
\end{tabular}

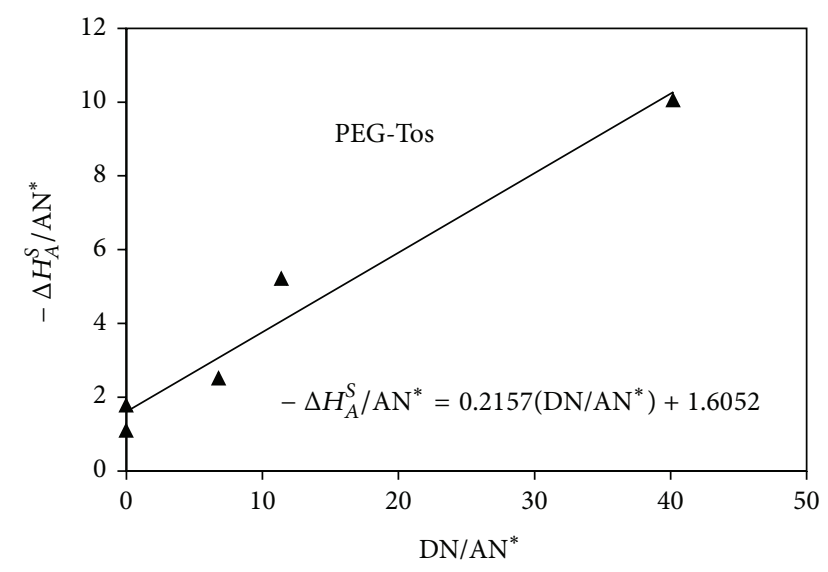

Figure 8: The plot of $-\Delta H_{A}^{S} / \mathrm{AN}^{*}$ versus DN/AN* for PEG-Tos.

the slope and $K_{D}$ as the intercept (Figures 7 and 8 for PEG and PEG-Tos, resp.).

\section{Conclusions}

The tosylated PEG was synthesized successfully according to FTIR-ATR and ${ }^{1}$ HNMR spectrums. The thermodynamic and surface interactions of nonpolar and polar solvents with PEG and PEG-Tos were characterized via IGC. The surface energy values of PEG were ranging from 23.1 to $12.6 \mathrm{~mJ} / \mathrm{m}^{2}$ and PEGTos from 34.4 to $28.9 \mathrm{~mJ} / \mathrm{m}^{2}$ with increasing temperature. The Lewis acid-base constants, $K_{A}$ and $K_{D}$, were found as follows: $K_{A}=0.09$ and $K_{D}=0.85$ for PEG and $K_{A}=0.22$ and
$K_{D}=1.61$ for PEG-Tos. According to the results, PEG and PEG-Tos presented a Lewis basic character and tosyl moiety increased the surface energy and basic nature of PEG.

\section{Conflict of Interests}

The authors declare that there is no conflict of interests regarding the publication of this paper.

\section{Acknowledgments}

The research was supported by the Scientific and Technological Research Council of Turkey (Project no. 107T697) and Scientific Research Projects Coordination Center of Yildiz Technical University (Project no. 2014-01-02-YL02).

\section{References}

[1] G. Pound, F. Aguesse, J. B. McLeary, R. F. M. Lange, and B. Klumperman, "Xanthate-mediated copolymerization of vinyl monomers for amphiphilic and double-hydrophilic block copolymers with poly(ethylene glycol)," Macromolecules, vol. 40, no. 25, pp. 8861-8871, 2007.

[2] F. Hua and E. Ruckenstein, "Synthesis of a water-soluble diblock copolymer of polysulfonic diphenyl aniline and poly(ethylene oxide)," Journal of Polymer Science, Part A: Polymer Chemistry, vol. 42, no. 9, pp. 2179-2191, 2004.

[3] D. Sakar, O. Cankurtaran, and F. Y. Karaman, "Thermodynamic interactions of a copolyester of bisphenol a with terephthalic acid and isophthalic acid with some solvents," Journal of Applied Polymer Science, vol. 98, no. 6, pp. 2365-2368, 2005.

[4] O. Yazici, F. Cakar, O. Cankurtaran, and F. Karaman, "Determination of crystallinity ratio and some physicochemical properties of poly(4-methyl-1-pentene)," Journal of Applied Polymer Science, vol. 113, no. 2, pp. 901-906, 2009.

[5] G. S. Dritsas, K. Karatasos, and C. Panayiotou, "Investigation of thermodynamic properties of hyperbranched aliphatic polyesters by inverse gas chromatography," Journal of Chromatography A, vol. 1216, no. 51, pp. 8979-8985, 2009.

[6] D. Sakar, T. Erdogan, O. Cankurtaran, G. Hizal, F. Karaman, and U. Tunca, "Physicochemical characterization of poly(tert-butyl acrylate- $b$-methyl methacrylate) prepared with atom transfer radical polymerization by inverse gas chromatography," Polymer, vol. 47, no. 1, pp. 132-139, 2006. 
[7] D. Sakar, O. Cankurtaran, and F. Karaman, "Evaluations on the miscibility of the mixtures of poly(2,6-dimethyl-1,4-phenylene oxide) and a copolyester of bisphenol-A," Polymers for Advanced Technologies, vol. 20, no. 3, pp. 291-297, 2009.

[8] C. Perruchot, M. M. Chehimi, M. Delamar, S. F. Lascelles, and S. P. Armes, "A physicochemical study of polypyrrole-silica nanocomposites by inverse gas chromatography," Journal of Colloid and Interface Science, vol. 193, no. 2, pp. 190-199, 1997.

[9] V. Oliva, B. Mrabet, M. I. Baeta Neves, M. M. Chehimi, and K. Benzarti, "Characterisation of cement pastes by inverse gas chromatography," Journal of Chromatography A, vol. 969, no. 12, pp. 261-272, 2002.

[10] F. Mutelet, G. Ekulu, and M. Rogalski, "Characterization of crude oils by inverse gas chromatography," Journal of Chromatography A, vol. 969, no. 1-2, pp. 207-213, 2002.

[11] G. Gumrukcu, S. Garikyan, G. K. Karaoglan, and D. Sakar, "Structural and surface characterization of newly synthesized D- $\pi$-D type Schiff base ligand: (1E,2E)-3-[4-(dimethylamino)phenyl]prop-2-en-1-ylidene) phenylamine," Journal of Chemistry, vol. 2013, Article ID 298205, 6 pages, 2013.

[12] H. Ocak, D. Sakar, F. Cakar, O. Cankurtaran, B. B. Eran, and F. Karaman, "Use of inverse gas chromatography for the physicochemical characterisation of a new synthesised liquid crystal: (S)-5-(2-methylbutoxy)-2-[(4- dodecyloxyphenyl)imino]methyl phenol," Liquid Crystals, vol. 35, no. 12, pp. 1351-1358, 2008.

[13] O. Yasa-Sahin, O. Yazici, B. Karaagac et al., "A new liquid crystal of considerable value for the separation of closely related solvents by gas chromatography," Liquid Crystals, vol. 37, no. 9, pp. 1111-1118, 2010.

[14] A. B. Nastasovi and A. E. Onjia, "Surface characterization of polymers by inverse gas chromatography," Journal of the Serbian Chemical Society, vol. 72, no. 4, pp. 403-406, 2007.

[15] J. E. Guillet and J. H. Purnel, Advances in Analytical Chemistry and Instrumentation Gas Chromatography, Wiley, New York, NY, USA, 1973.

[16] J. R. Conder and C. L. Young, Physicochemical Measurement by Gas Chromatography, Wiley-Interscience, New York, NY, USA, 1979.

[17] R. L. Grob, Modern Practice of Gas Chromatography, WileyInterscience, New York, NY, USA, 1995.

[18] A. V. Kiselev, "Non-specific and specific interactions of molecules of different electronic structures with solid surfaces," Discussions of the Faraday Society, vol. 40, pp. 205-218, 1965.

[19] F. L. Riddle Jr. and F. M. Fowkes, "Spectral shifts in acid-base chemistry. 1. van der Waals contributions to acceptor numbers," Journal of the American Chemical Society, vol. 112, no. 9, pp. 3259-3264, 1990.

[20] G. M. Dorris and D. G. Gray, "Adsorption of $n$-alkanes at zero surface coverage on cellulose paper and wood fibers," Journal of Colloid and Interface Science, vol. 77, no. 2, pp. 353-362, 1980.

[21] C. S. Flour and E. Papirer, "Gas-solid chromatography: method of measuring surface free energy characteristics of short fibers. 2. Through retention volumes measured near zero surface coverage," Industrial \& Engineering Chemistry Product Research and Development, vol. 21, pp. 666-669, 1982.

[22] Z. Y. Al-Saigh, "Inverse gas chromatographic characterization of poly(ethylene oxide)," Polymer, vol. 40, no. 12, pp. 3479-3485, 1999.

[23] K. Batko and A. Voelkel, "Inverse gas chromatography as a tool for investigation of nanomaterials," Journal of Colloid and Interface Science, vol. 315, no. 2, pp. 768-771, 2007. 

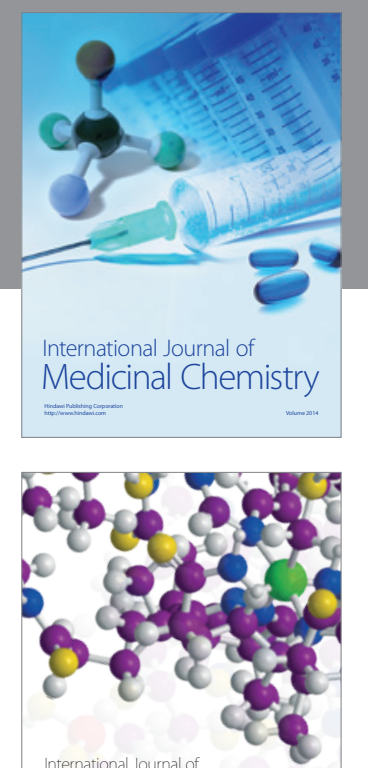

\section{Carbohydrate} Chemistry

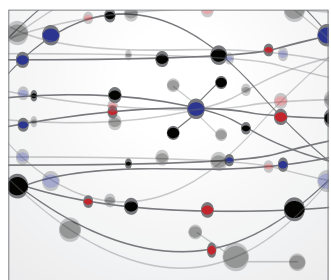

The Scientific World Journal
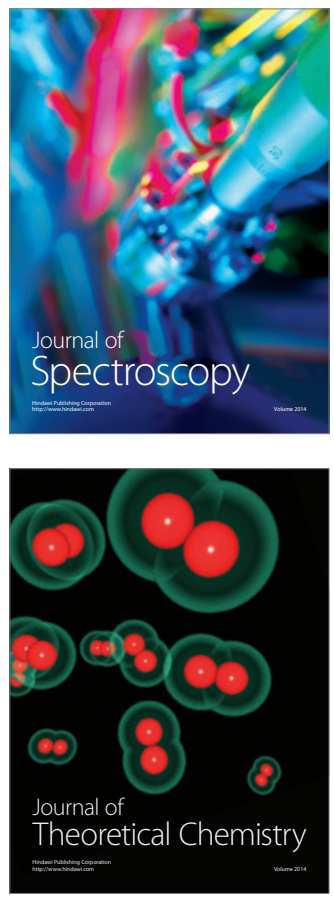
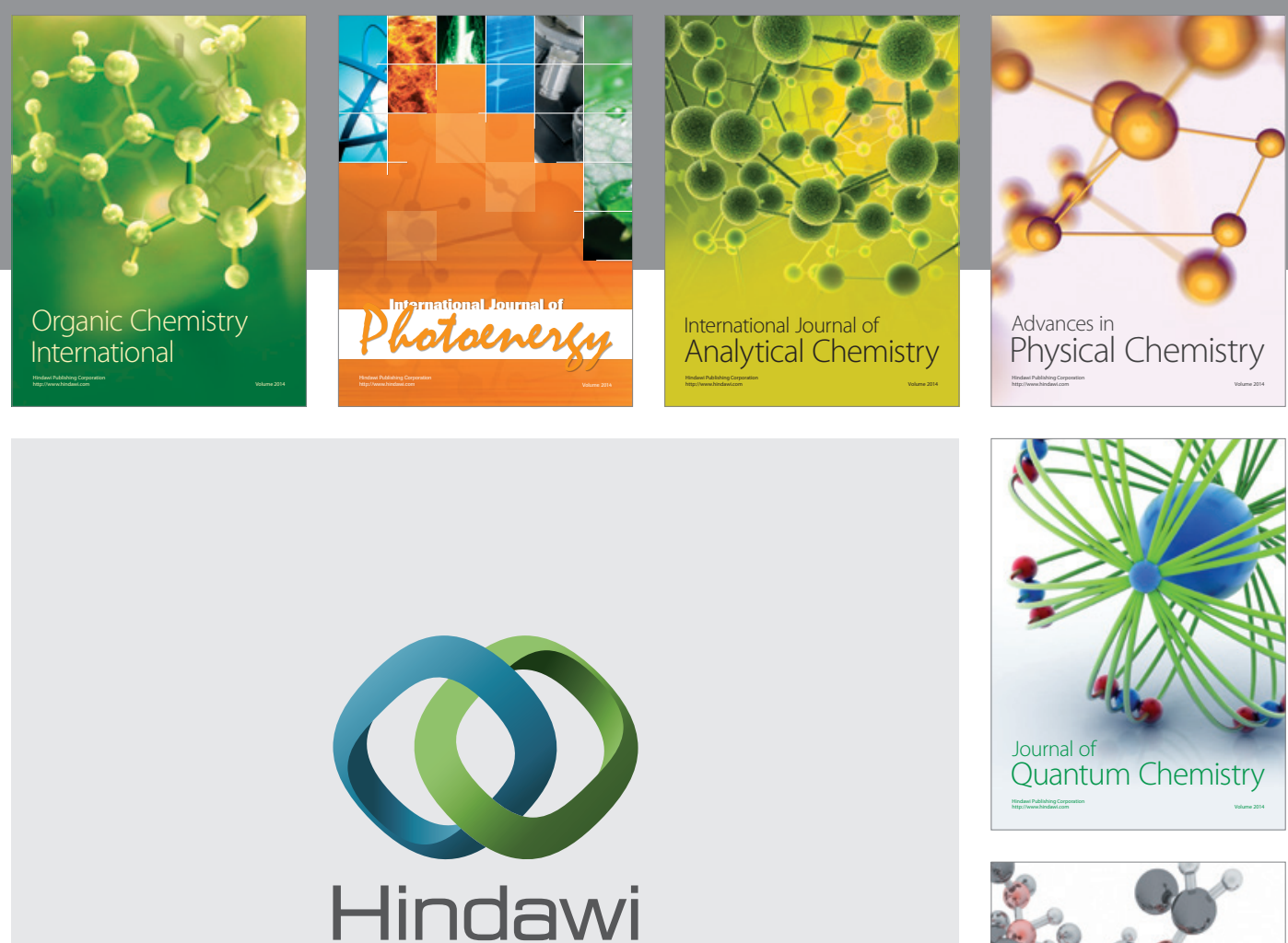

Submit your manuscripts at

http://www.hindawi.com

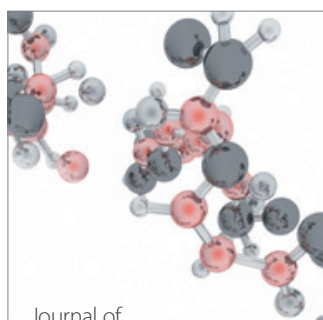

Analytical Methods

in Chemistry

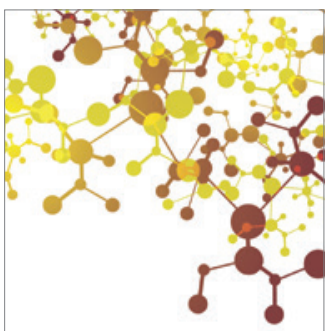

Journal of

Applied Chemistry

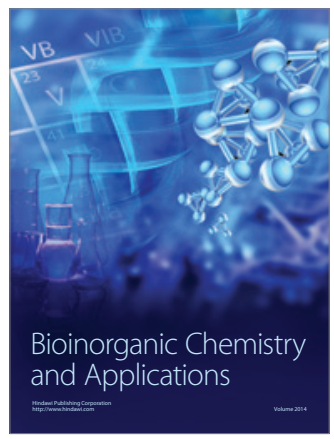

Inorganic Chemistry
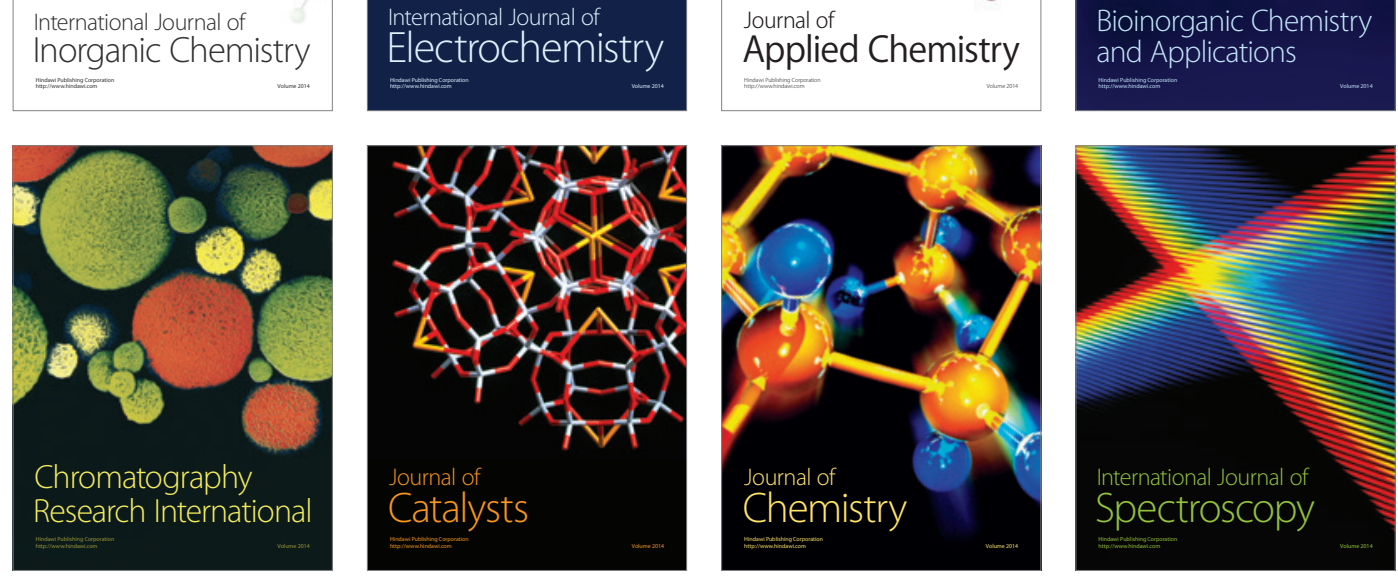